\title{
Forewarning model development for mustard aphid (Lipaphis erysimi Kalt.) at Bharatpur and Hisar
}

\section{MEHNAJ THARRANUM A ${ }^{1}$., Y. P. SINGH ${ }^{2}$, BASANT K. KANDPAL ${ }^{3}$, K. K. SINGH ${ }^{1}$ and AVINASH CHANDRA PANDEY ${ }^{4}$}

${ }^{1}$ Agromet Advisory Services Division, India Meteorological Department, New Delhi.

${ }^{2}$ Crop Science Division, ICAR, New Delhi.

${ }^{3}$ ICAR Research Complex for NEH Region, Lembucherra, Tripura.

${ }^{4} \mathrm{~K}$. Banerjee Centre of Atmospheric and Ocean Studies, University of Allahabad, Allahabad (UP)

e-mail:mtharranum@gmail.com

\begin{abstract}
The weekly aphid population on timely sown mustard crop and daily weather parameters recorded at ICAR-Directorate of Rapeseed-Mustard Research, Bharatpur and Hisar stations, during rabi seasons of 2003-04 to 2013-14 were used to develop forewarning model for aphid. In most of the cases, the appearance of population and its peak activity occurred during 51 standard meteorological week (SMW) and $8 \mathrm{SMW}$. The study revealed that the thermal time or growing degree days (GDD) consistently explained the aphid multiplication significantly in all seasons. The impact of other weather parameters on pest population was observed to be significant only in some seasons. The aphid population increased exponentially with increase in GDD. Further, the exponential coefficient varied among the varieties. The population build up was compared with the model predicted values in three common species (Brassica juncea, B. rapa ssp. sarson and B. napus) grown at two stations. The results revealed that the predicted values derived using the model, were in close agreement with those of the observed.
\end{abstract}

Key words: Aphid, apterous, nymph, thermal time, forewarning model.

The oilseed mustard crop is grown mostly in north and north-west India whose production and productivity are adversely affected by mustard aphids. Lipaphis erysimi Kaltenbach (mustard) is an important pest constraint in crop husbandry of oilseed Brassicas in India causing between 20 to 50 per cent of avoidable yield losses in mustard (Chakravarty and Gautam, 2002). The population dynamics of this sucking pest seems to be highly influenced by prevailing weather conditions, especially temperature.

Both nymphs and adults suck sap from tender portion of the plants. Tracking the economic threshold level (ETL) of the pest is an essential task in Indian scenario, where there has been an unprecedented use of pesticides. Real time forewarning of the pest population would be useful to the farming community for judicious use of pesticides. As apterous nymph and adults are more harmful than dispersing alate population, an attempt to track the growth of apterous aphid population on rising limb using weather parameters and develop forewarning model. Linked with medium range weather forecast, would enable decision makers to know the timing of pest population crossing ETL in advance and this can be operationalized to forewarn against the aphid pest population in future under Gramin Krishi Mausam Sewa (GKMS) scheme.

\section{MATERIALS AND METHODS}

\section{Field trials}

Based on field experiments conducted at two stations viz., Bharatpur $\left(27^{\circ} 12^{\prime} \mathrm{N} ; 77^{\circ} 27^{\prime} \mathrm{E}\right)$ and Hisar $\left(29.15^{\circ} \mathrm{N}\right.$, $75.7^{\circ} \mathrm{E}$ ) for 11 consecutive rabi seasons from 2003-04 to 2013-14 under All-India Coordinated Research Project on Rapeseed and Mustard, weekly apterous mustard aphid data (from Directorate of Rapeseed and Mustard Research) were collected. The varieties considered for study at Bharatpur were: PCR-7 (Rajat) (Brassica juncea); BSH-1 (B. rapa ssp. sarson) and NUDB-09 (B. napus ssp. oleifera var. annua). The varieties considered at Hisar were: RH-30 (Brassica juncea); BSH-1 (B. rapa ssp. sarson) and HNS-9605 ( $B$. napus ssp. oleifera var. annua). All the data relied on natural population dynamics of the average aphid infesting the 10 cm tip of central twig over timely sown crop in at each 
station. No pest protection measures were taken against aphid pest in the study area.

The model construction was initiated over the population dynamics of aphids on two species: Brassica juncea and B.rapa var trilocularis, at Bharatpur. The contrast between the two species was considered on the basis of duration taken for maturity and varietal aphid pest resistance. The maturity period for variety of Brassica juncea is 134 days at Bharatpur (Misra and Kumar, 2009) and that of B.rapa var trilocularis is 150-155 days. As Chakravarty and Gautam (2002) observed that the occurrence, peak, decrease and dispersal of aphid population are dependent on the plant phonological phenological events, a difference in days to maturity between two varieties selected may provide a deep insight into development of forewarning model. The two species selected also differ in pest resistance capabilities (Sachan and Purwar (2007).

\section{Weather data analysis}

The daily weather data comprising of maximum temperature $\left(\operatorname{Tmax}^{\circ} \mathrm{C}\right)$, minimum temperature $\left(\operatorname{Tmin}^{\circ} \mathrm{C}\right)$, morning relative humidity ( $\mathrm{RH} \mathrm{I}, \%)$, evening relative humidity (RH II, \%), rainfall (mm), bright sunshine hours (BSS, hours), wind speed (WS, kmph) for years 2003 to 2014, was analysed were used to derive, the weekly means of weather parameters (Tmax, Tmin, RH I, RH II, BSS and WS) from SMW 1 to week of peak population, for all the seasons were derived. Also, weekly accumulated rainfall, weekly highest Tmax, weekly lowest Tmin, weekly highest RH I, weekly highest RH II, highest day temperature, lowest night temperature, weekly mean day temperature and weekly mean night temperature were computed. The following equation by Petricevic was used to compute the day and night time temperatures from maximum and minimum temperatures, cited by Gomes (1983).

$$
\begin{aligned}
& t d=\frac{T \max +T \min }{2}+\frac{T \max -T \min }{4 \pi} \times \frac{(11+T S)}{12-T S} \times \operatorname{Cos} \alpha \\
& t n=\frac{T \max +T \min }{2}-\frac{T \max -T \min }{4 \pi} \times \frac{(11+T S)}{T S} \times \operatorname{Cos} \alpha \\
& \alpha=\frac{11-T S}{11+T S} \pi
\end{aligned}
$$

where, $t d=$ average day time temperature $\left({ }^{\circ} \mathrm{C}\right) ; t n=$ average night time temperature $\left({ }^{\circ} \mathrm{C}\right) ; \operatorname{Tmax}=$ daily maximum temperature; $\left({ }^{\circ} \mathrm{C}\right) ; \operatorname{Tmin}=$ daily minimum temperature; $\left({ }^{\circ} \mathrm{C}\right)$; $ð=3.1416$; and $T S=$ time of sunrise $=(12-\mathrm{N} / 2)$ with $\mathrm{N}=$ day length. (hours and decimal hours) (Table 1).

The growing degree days (GDD) from SMW $1^{\text {st }}$ to week of peak population for all the seasons were also computed using base temperature $\left(\mathrm{T}_{\text {base }}\right)$ of $3.04^{\circ} \mathrm{C}$ for mustard aphid L.erysimi (Godoy and Cividanes, 2001).

\section{RESULTS AND DISCUSSION}

\section{Correlation study}

The correlation between different weather parameters and aphid data of only B. juncea variety PCR-7 at Bharatpur, for each season were calculated. Using step-wise linear regression method, the highly significant weather variable for each year was selected. The weekly data for correlating weather with aphid population included only from a period between SMW 1 and week attaining peak aphid population, as the tracking of appearance of the population to peak was found to be the most needed for effective management, as the crop reaches flowering stage during this period, which is the most preferred stage for aphid pest. Chakravarty and Gautam (2004) also observed that the mustard aphids have a preference for flowering stage of the crop. Among those weather parameters which have highly significant correlations with aphids only one parameter, which has highly significant inter-co linearity with other parameters was chosen. The main aim of selecting only one highly significant parameter was to construct a model having stability with reduced complexity.

Out of ten seasons, eight seasons had GDD as a common variable influencing aphid population, whose correlation coefficients ranged between $0.795 *(2007-08)$ and $0.982 * *(2013-14)$. The inter-co linearity between GDD and other significant parameters was also observed to be highly significant (Table 1). Thereafter, GDD was shortlisted as the parameter having highly significant relation with aphid and other significant weather parameters and was used for development of the model. GDD as a successful yardstick for aphid population growth has been suggested by many researchers previously. Chakravarty and Gautam (2004) concluded that lower the degree day accumulation rates in January, higher the probable peak aphid population.

\section{Development of forewarning model}

It was found that in most of the cases, prevalence of mean weekly maximum temperature between 18 and $24^{\circ} \mathrm{C}$ and mean weekly minimum temperature between 4 and $6^{\circ} \mathrm{C}$ was conducive for aphid appearance at Bharatpur. As the 


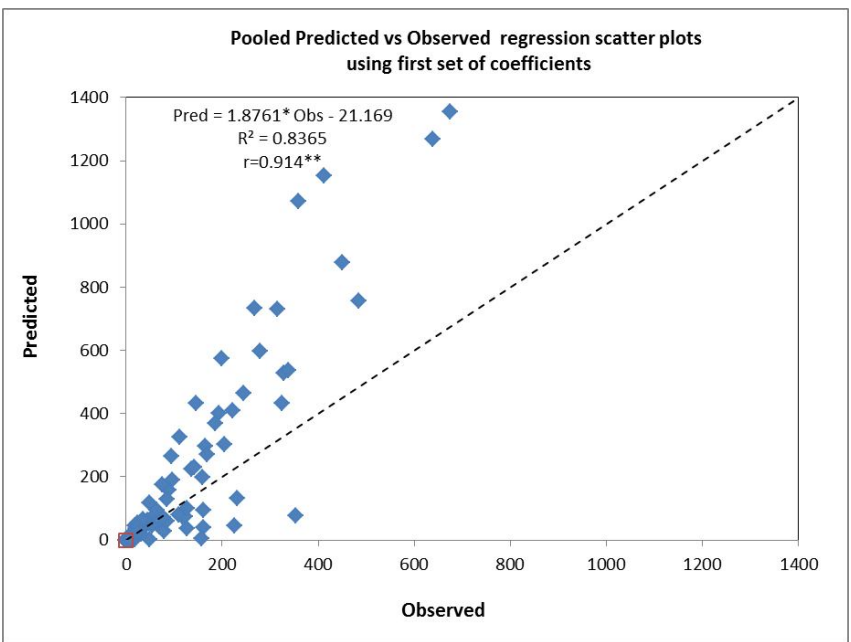

Fig. 1: Observed and predicted scatter plots of aphid population using first set of coefficients
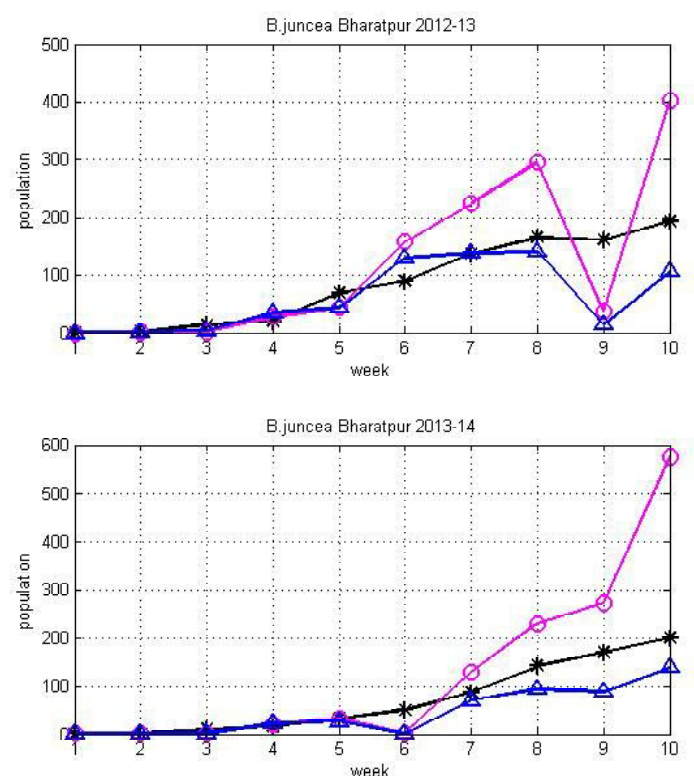

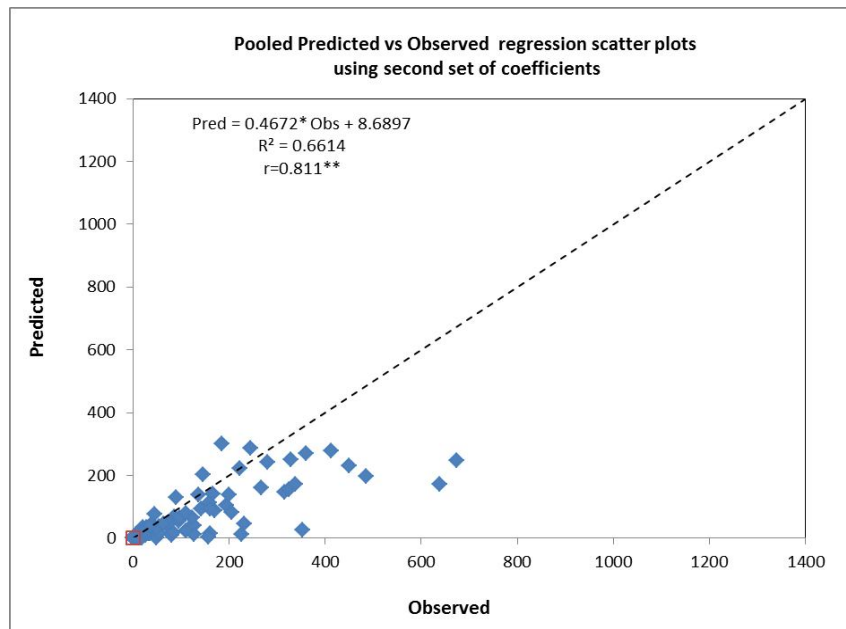

Fig. 2.: Observed and predicted scatter plots of aphid population using second set of coefficients
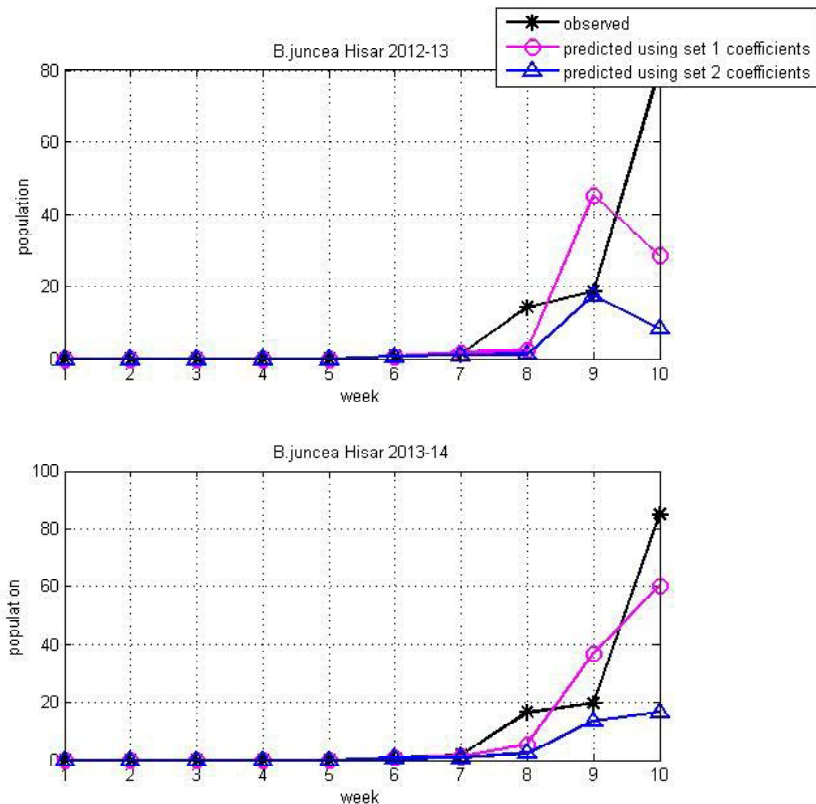

Fig. 3. : Observed vs. predicted aphid population of B.juncea seasons 2012-13 and 2013-14, using model coefficients of set 1 and 2 at Bharatpur and Hisar
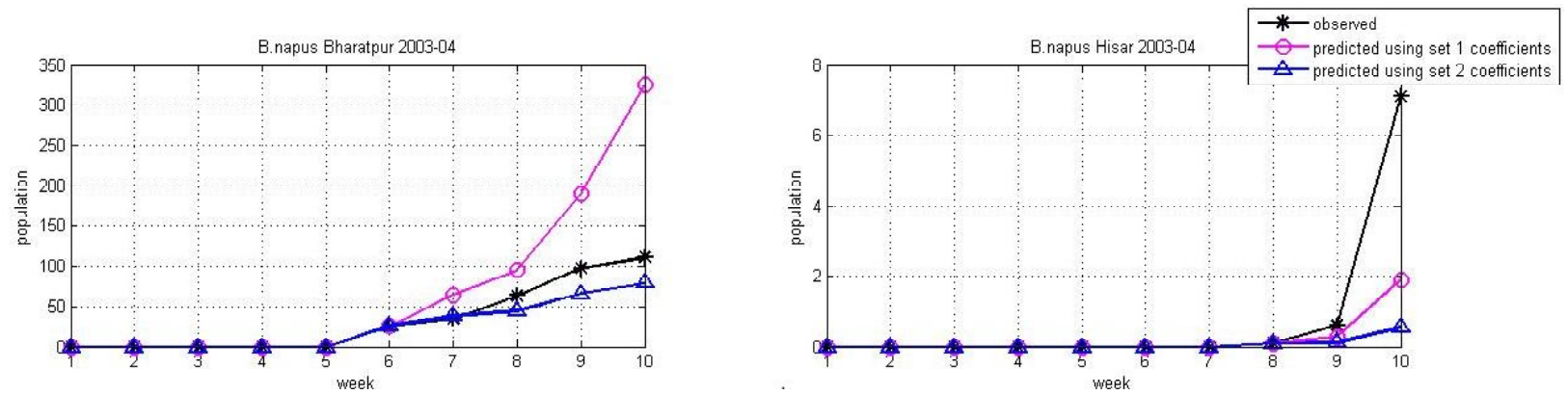

Fig. 4. : Observed vs. predicted aphid population of B.napus season 2003-04, using model coefficients of set 1 and 2 at Bharatpur and Hisar 

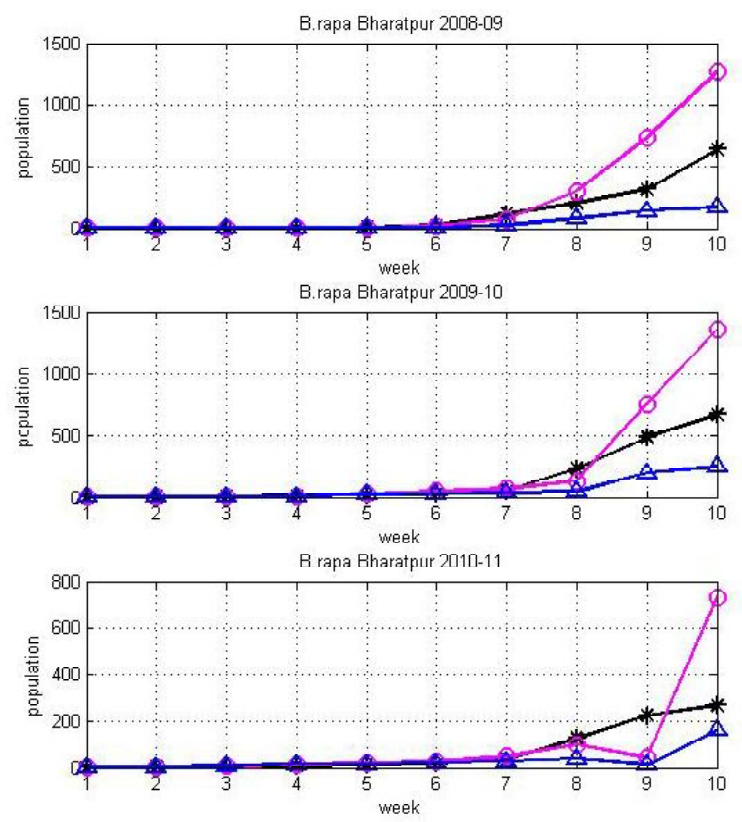
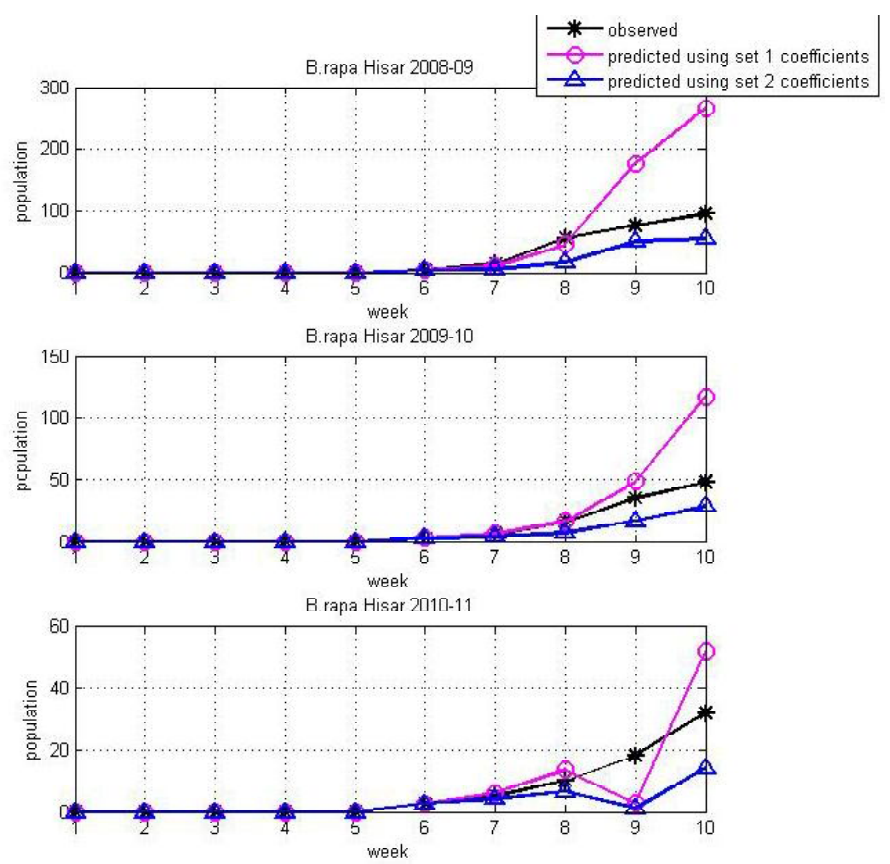

Fig. 5. : Observed vs. predicted aphid population of B.rapa ssp. sarson seasons 2008-09, 2009-10 and 201011, using model coefficients of set 1 and 2 at Bharatpur and Hisar.
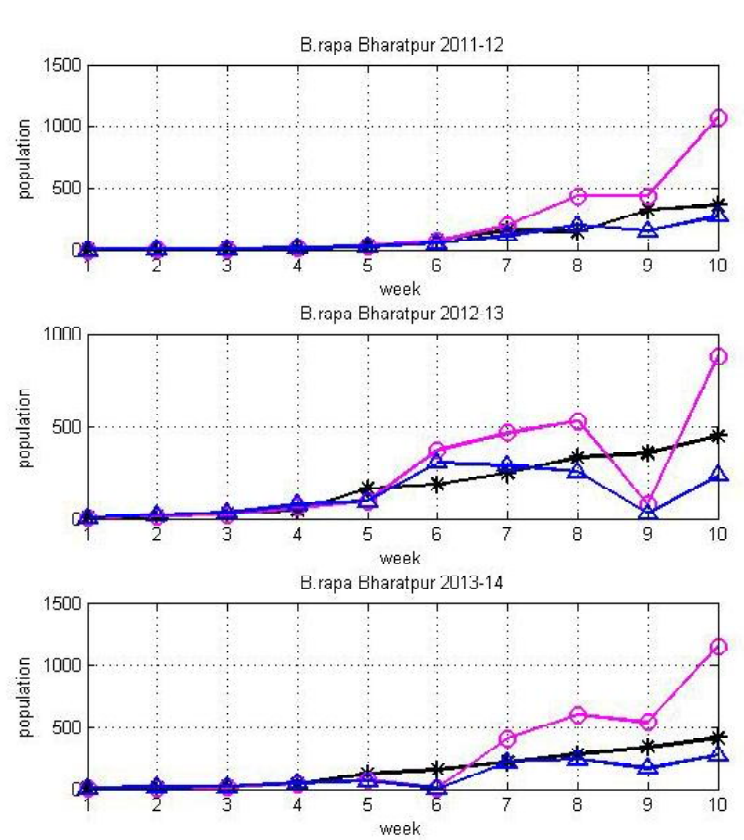
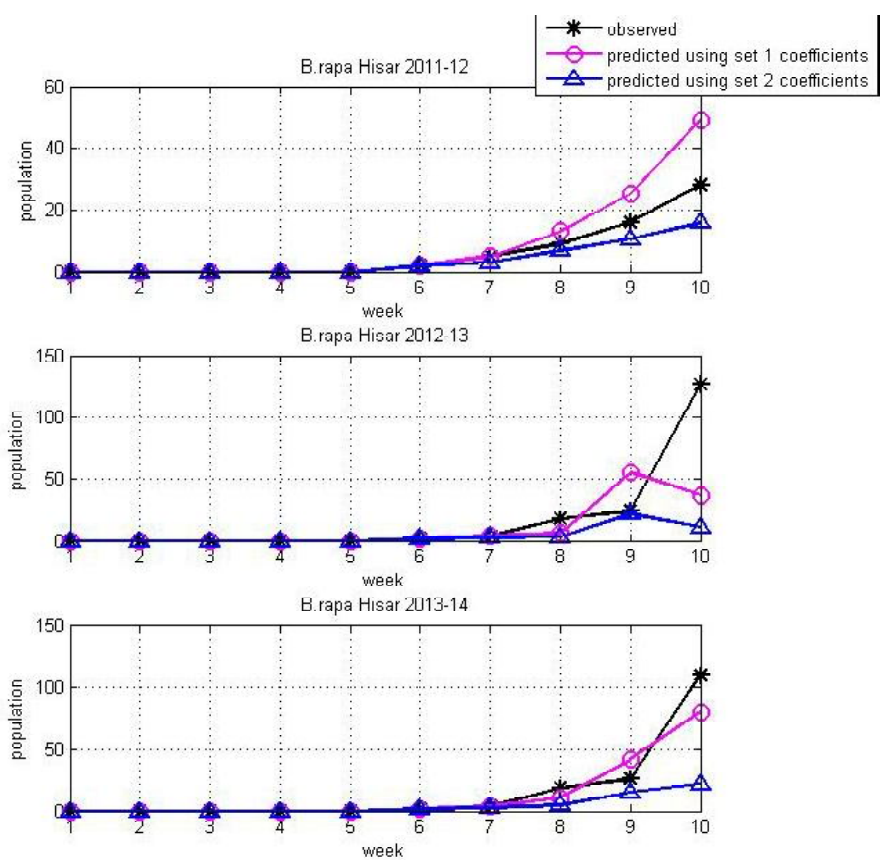

Fig. 6. : Observed vs. predicted aphid population of B.rapa ssp. sarson seasons 2011-12, 2012-13 and 201314, using model coefficients of set 1 and 2 at Bharatpur and Hisar.

pest build-up began in the mid December and January in some of the cases, it was found essential that for development of an effective model, the computation of thermal time must begin as early as mid-December. Thereafter GDD were accumulated from SMW 51 of every season, and ended at SMW 8, spanning a time span of 10 weeks. Corresponding aphid data from SMW 51 to SMW 8, were considered for construction of model, deleting out those weeks which had a rain spell, in order to track the impact of GDD over aphid population, effectively. Further scope for improvement and correction in the model was provided by siphoning out the aphid population data during rainy weeks for model 
Table 1 : Highly significant weather parameters, their Pearson's correlation coefficients with weekly aphid population and intercollinearity

\begin{tabular}{llll}
\hline Season & $\begin{array}{l}\text { Weather parameters having highly } \\
\text { significant correlation with aphid } \\
\text { population }\end{array}$ & $\begin{array}{l}\text { Pearson's correlation } \\
\text { coefficient }(\mathrm{r})\end{array}$ & Inter-collinearity \\
\hline $2003-04$ & GDD & $0.890^{* *}$ & $-0.916^{* *}$ \\
& Mean RH I & $-0.832^{*}$ & \\
$2004-05$ & Mean Tmax & $0.94^{* *}$ & $0.99^{* *}$ \\
& Mean Day Temperature & $0.952^{* *}$ & \\
$2006-07$ & GDD & $0.898^{* *}$ & $0.877^{* *}$ \\
& Mean RH I & $0.911^{* *}$ & \\
$2007-08$ & GDD & $0.795^{*}$ & $0.828^{*}$ \\
& Mean BSS hours & $0.904^{* *}$ & \\
$2008-09$ & GDD & $0.899^{* *}$ & $-0.810^{*}$ \\
& Weekly highest RH I & $-0.934^{* *}$ & \\
$2009-10$ & GDD & $0.847^{*}$ & $-0.939^{* *}$ \\
& Weekly highest RH II & $-0.902^{* *}$ & \\
$2010-11$ & Mean Tmin & $0.978^{* *}$ & $0.973^{* *}$ \\
& Mean Night temperature & $0.923^{* *}$ & \\
$2011-12$ & GDD & $0.932^{* *}$ & $0.905^{* *}$ \\
& Mean Tmax & $0.847^{*}$ & $0.988^{* *}$ \\
& GDD & $0.972^{* *}$ & \\
\hline
\end{tabular}

(* significant at 0.05 level; ** significant at 0.01 level) construction, as rain causes mechanical damage to the pest. A separate model was then constructed to correct the predictions of aphid population remaining after a spell of rain.

Three things were predominantly kept as a base :

i). Populations in an unlimited environment display exponential (geometric) growth. Hence insect population dynamics up to peak population was considered to grow exponentially with the increase in growing degree days.

ii). The rate of development of poikilothermic organisms like insects is inversely proportional to degree-days. This was most widely used method for predicting physiological age and time for populations of poikilothermic organisms (Gutierrez, 1996). Hence the rate at which weekly population increase was considered to be inversely proportional to GDD. Dhaliwal et al. (2006) also reported that the aphid infestation index generally showed a negative correlation with temperature during both 2003-04 $\left(D_{1}\right)$ and 2004-05 $\left(D_{1}\right.$ and $\left.D_{2}\right)$ years.

iii). For model to be dynamic in nature, the insect population growth rate was modelled as an increasing function of the current insect population and time (Sunding and Zivin, 2000). Population was computed as an exponential function of previous population, while constructing the aphid forewarning model.

Model framework was developed on these views, which was as follows:

For $\mathrm{i}^{\text {th }}$ week: Aphid $_{(\mathrm{i})}=\operatorname{Aphid}_{(\mathrm{i}-1)} \mathrm{x} \exp \left(\operatorname{Rate}_{(\mathrm{i})} \mathrm{x} \mathrm{GDD}_{(\mathrm{i})}\right)$.

In this model, the rates were first obtained for every week aphid growth, of all seasons. It was observed that the 
Table 2: Per cent correct predictions of aphid population levels using model coefficients of set 1 and 2 in various species at Bharatpur and Hisar stations.

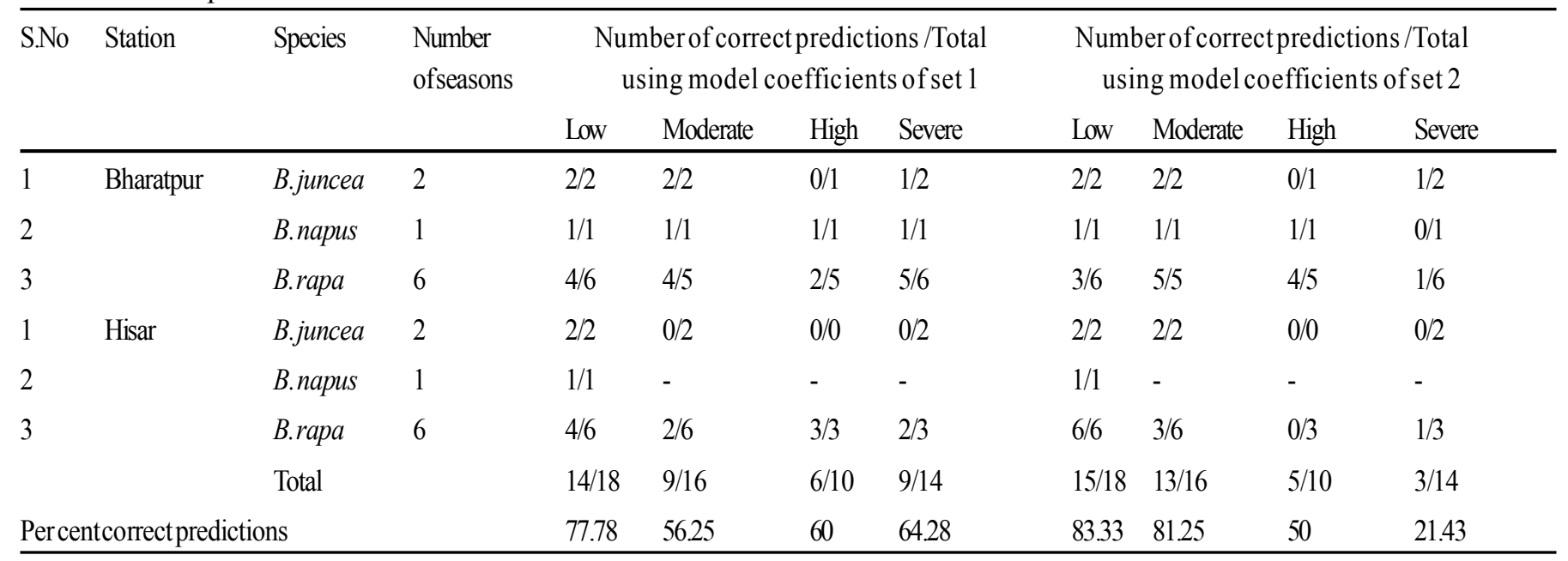

Table 3: Performance of aphid population levels using model coefficients of set 1 and 2 in various species.

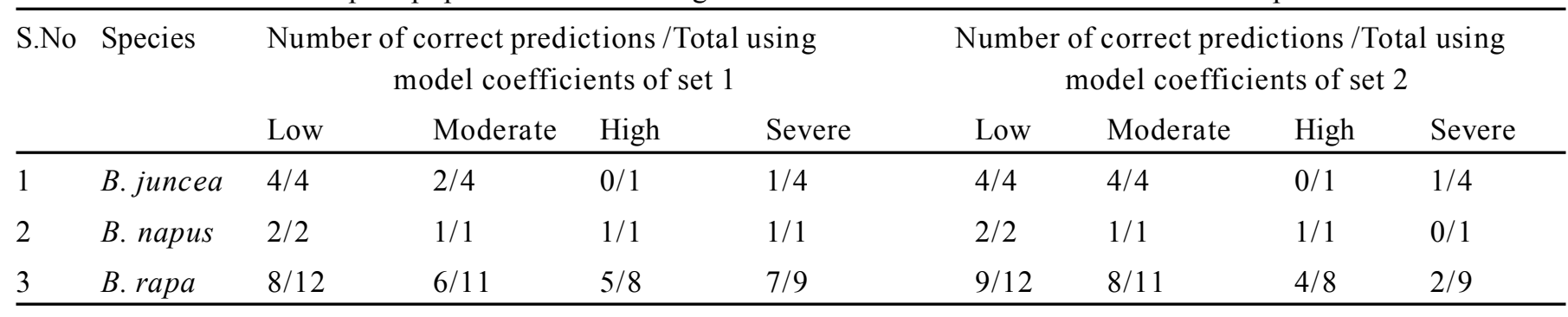

rates varied every week and these were altogether in the descending order: from 0.006 for SMW 52 to 0.0005 for SMW 8. The individual rates of each week of every season were then correlated with the corresponding accumulated thermal time. It was found that they were negatively correlated, with a coefficient of $-0.446^{* *}$. This proves that the rate of development of insects is inversely proportional to degree-days (Gutierrez, 1996). Hence, the rate of the model was represented as follows:

Rate $_{(\mathrm{i})}=\mathrm{A}+\left(\mathrm{B} / \mathrm{GDD}_{(\mathrm{i})}\right)$;

where $\mathrm{A}$ and $\mathrm{B}$ are intercept and slope respectively.

Regression analyses were carried out for aphid population of eight rabi seasons (2003-04 to 2011-12) of PCR-7 variety of B. juncea and five seasons (2007-08 to 2012-13) of YST-151 variety of $B$. rapa var. trilocularis at Bharatpur. Thereafter, intercept and slope of the rate were ascertained for both $B$. juncea and B. rapa var trilocularis (A1, B1 and A2, B2 respectively).

For B. juncea, $\mathrm{A} 1=0.0010269 ; \mathrm{B} 1=0.465377,\left(\mathrm{R}^{2}=0.275^{* *}\right)$. (set 1 coefficients);

For B. rapa vartrilocularis, A2=-0.0022407; B2=1.41471; $\mathrm{R}^{2}=0.586^{* *}$. ( $\operatorname{set} 2$ coefficients $)$
(** significant at 0.01 level)

These coefficients estimated for both the varieties were represented as set 1 (A1 and B1) and set 2 (A2 and B2) in future validation and calibration studies.

\section{For corrections during weeks with rainfall}

The predictions for aphid populations for weeks having rain spell were first made using the above thermal time based model. The ratios of these predictions to the observed aphid (of training datasets) were considered to be rainfall correction factor ' $x$ '. The model for rainfall correction factor was constructed using the weekly accumulated rainfall data. Thus using correction factor ' $x$ ', new corrected predictions were made, which eliminated the effects of mechanical damage over aphid population during rainfall.

For $i^{\text {th }}$ week:

$\mathrm{x}_{(\mathrm{i})}=1.686-0.290$. (accumulated rainfall $\left.{ }_{(\mathrm{i})}\right)+0.027$. $\left(\left(\text { accumulated rainfall }_{(\mathrm{i})}\right)^{2}\right) ; \quad\left(\mathrm{R}^{2}=0.782 * *\right)$

Corrected prediction $_{(\mathrm{i})}=$ Predicted aphid population using thermal time based model $_{(\mathrm{i})} / \mathrm{x}_{(\mathrm{i})}$;

\section{Validation results}

The predicted versus observed 1:1 regression scatter 
plots of pooled aphid population data of B.juncea, B.rapa and B.napus (comparison between predictions made by two sets of coefficients) (Fig. 1 and 2), revealed that the $\mathrm{R}^{2}$ values were better for predictions made by set 1 coefficients $\left(\mathrm{R}^{2}=0.84^{* *}\right)$, than by set 2 coefficients $\left(\mathrm{R}^{2}=0.66^{* *}\right)$. Despite this, it also revealed that only those values which were below a certain severe level (60), can be better predicted. As the values became higher, the scattering of the points also became wider, suggesting the errors may increase if predictions were made for severe pest population levels. The root mean square deviation (RMSD) of the pooled predicted values made by set 1 coefficients with respect to observed values below severe level was estimated to be 9.9, whereas that of the pooled predicted values made by set 2 coefficients with respect to observed values below severe level was estimated to be 7.9. Hence, the observations and predictions, for better interpretation, were represented qualitatively rather than quantitatively. This may also serve the purpose to prepare ground to the forewarning model for its better operationalization in decision making on timing of pesticide spray. Four categories of outcome were made according to the population of aphids per $10 \mathrm{~cm}$ of central shoot:

(i) Low (0-10); (ii) Moderate (11-29); (iii) High (30-60); and (iv) Severe $(>60)$.

The category 'high' shows economic threshold level (ETL) of the aphid population, attaining which spray of pesticide is advised.

The validation data sets consisted of 2012-13 and 2013-14 rabi seasons of B.juncea, 2003-04 rabi season of B.napus and six consecutive rabi seasons (2008-09 to 2013-14) of B.rapa ssp. sarson at Bharatpur and Hisar. The observed pest population and predictions made using thermal time model having set 1 coefficients (A1 and B1) and set 2 coefficients (A2 and B2), were compared and are presented in Fig. 3 to 6 . Only the rising limb of the population curve of pest was traced, considering the fact that the population naturally decreases exponentially as the crop draws near to physiological maturity. Hence tracking of pest during flowering stage of the crop was considered more important than tracking the entire rise and fall of population. The rain events at $9^{\text {th }}$ week (SMW 7) of 2012-13 rabi season and $6^{\text {th }}$ week (SMW 4) of 2013-14 season, predicted a significant reduction in apterous aphid population at Bharatpur, but it did not match with the observed population. This may be attributed to the fact that the recording of observations might have been done before the rain spell.
The per cent correct predictions using model having set 2 coefficients (A2 and B2) were better than set 1 coefficients (A1 and B1) in both low and moderate levels of pest status, making for 83.3 and 81.3 per cent for low and moderate categories, respectively (Table 2 ). The per cent correct predictions were 60 and 64.3, for high and severe categories, respectively, using model having set 1 coefficients, which were found better than set 2 coefficients, which were only 50 and 21.4 per cent for these categories. As tracing economic threshold level (ETL) was more important, the model having set 1 coefficients was considered for future calibrations because its predictions for high (ETL) and severe categories (above ETL) were more accurate (despite having lower $\mathrm{R}^{2}$ value) than those made using set 2 coefficients.

Among species, the performance of the model using set 1 coefficients in predicting aphid population of $B$. napus and B.rapa was considered much better in high and severe categories (Table 3). Considering the higher prediction accuracy provided by the model using set 1 coefficients, it may be used further in forewarning the mustard aphids qualitatively. This bio-model needs further improvement and calibrations regarding accuracy, due to rainfall and fog (dense and moderate category fog) as a mechanical damage factor and corrections over various varietal responses at various stations.

\section{CONCLUSION}

Since the population growth of insect pests predominantly depended upon thermal time, its function was used to predict the build-up of the aphid population. The thermal time based model using set 1 coefficients (A1=0.0010269; B1=0.465377), developed using infestation on B.juncea at Bharatpur, was found to be more accurate in predicting aphid pest population, with the per cent correct predictions of 60 and 64.3 , for high and severe categories, respectively. The dynamicity of the model, attributed to its accounting of previous week's pest status, makes it more adjustable to the changing pest population and prediction in real-time. Calibrations and corrections of the coefficients every week, over various stations and wide range of varieties and corrections due to rainfall and fog, are prime requisites under consideration.

\section{ACKNOWLEDGEMENTS}

We duly acknowledge the Director of DRMR, Bharatpur, for providing necessary multi-year field 
experiment data generated under AICRP on Rapeseed \& Mustard. We also duly acknowledge sincere guidance from Dr. NVK Chakravarty, Former Head, Agricultural Physics Division, IARI, New Delhi, during the entire course of study and his constant efforts in motivating researchers like us to take up studies which would benefit farmer community by forewarning pests and diseases on real-time basis.

\section{REFERENCES}

Chakravarty, N.V.K. and Gautam, R.D. (2002). Forewarning MustardAphid, Cooperating Centre for Mustard NATPMMP-17 (Program-6), Division of Agricultural Physics, IndianAgricultural Research Institute, New Delhi, pp. 23.

Chakravarty, N.V.K. and Gautam, R.D. (2004). Degree day based forewarning system for mustard aphid. $J$. Agrometeorol., 6 (2): 215222.

Dhaliwal, L.K., Hundal, S.S., Kular, J.S., Chahal, S.K. andAneja, A., (2006). Musatrd aphid infestation and yield of raya as affected by dates of sowing and meteorological parameters. JRes.Punjab Agric. Univ, 43 (2): 98-101.
Godoy, K.B., and Cividanes, F.J. (2001). Exigênciastérmicas e previsào de picospopulacionais de Lipaphis erysimi (Kalt.) (Homoptera: Aphididae). Neotropical Ent., 30:369-371.

Gomes, R.A. (1983). Pocket computers in agrometeorology. FAOPlant Production and Protection PaperNo. 45, FAO, Rome, Italy.

Gutierrez,A. P. (1996). Applied Population Ecology:A SupplyDemandApproach. New York: pp.31.

Mishra,A.K. and Kumar, A. (2009). Characterization of Indian mustard (Brassica juncca L.) geram plasm for economic traits. Cruceferae Newsletter, 28: 27-30.

Sachan, G.C., and Purwar, J.P. (2007). Integrated Insect Pest Management in Rapeseed and Mustard. Entomology: Novel Approaches. New Delhi. 399-423.

Sunding, D. and Zivin, J. (2000). Insect population dynamics, pesticide use, and farmworker health. Amer. J. Agr. Econ., 82 (August): 527-540. 